\title{
Neutronics characterization of an erbia fully poisoned PWR assembly by means of the APOLLO2 code
}

\author{
Roberto Pergreffi ${ }^{*}$, Davide Mattioli, and Federico Rocchi \\ ENEA, Via Martiri di Monte Sole 4, 40129 Bologna, Italy
}

Received: 19 October 2016 / Received in final form: 19 December 2016 / Accepted: 24 January 2017

\begin{abstract}
Recently, increasing demands on the reduction of fuel cycle costs have led to higher burnup fuel designs. According to the erbia-credit super high burnup fuel concept, developed by mixing low content of erbia to $\mathrm{UO}_{2}$ powder directly after reconversion process so that all fuel pins in a given fuel assembly are homogeneously doped, the present study aims to characterize, from a neutronic point of view, a $17 \times 17$ pressurized water reactor assembly enriched to $10.27 \mathrm{wt} . \%$ in ${ }^{235} \mathrm{U}$ with an erbia content of 1 at.\% (i.e. $0.7 \mathrm{wt} . \%$ ) by means of the deterministic neutronic code APOLLO2. For this purpose, a simplified thermal-hydraulic analysis was performed in order to evaluate the effects on fuel thermal conductivity of adding erbia to uranium oxide. The results obtained allow to conclude that an Er-doped assembly enriched to $>5 \mathrm{wt} . \%$ in ${ }^{235} \mathrm{U}$ represents an advantageous solution for very long fuel cycles, and it is so suited for very high burnups.
\end{abstract}

\section{Introduction}

The idea of using neutron poison materials was originally developed in order to increase the allowable initial core fuel enrichment. In fact, the high neutron absorption cross sections of such materials permit to compensate, during the early stages of core life, the excess reactivity due to higher initial enrichment. Moreover, they burn out somewhat faster than fuel so that their contribution in core life in terms of negative reactivity is negligible [1].

Erbia's $\left(\mathrm{Er}_{2} \mathrm{O}_{3}\right)$ role as a poison in light water reactor (LWRs) was first highlighted in 1970, but only late in the 1980s that it was recognized as an alternative absorber to gadolinia $\left(\mathrm{Gd}_{2} \mathrm{O}_{3}\right)$ and, like that, mixed with fissile material in a small number of fuel pins of an assembly [2]. From a safety point of view, erbium was found to be very effective at minimizing radial power peaking thanks to relatively low thermal absorption effective cross section ( $162 \pm 8$ barns vs. 49,000 \pm 1000 barns of gadolinium) and at controlling transients thanks to the higher resonance integral $(740 \pm 10$ vs. $390 \pm 10$ barns). Moreover, erbium has a rather short evolution chain and, differently from gadolinium, its efficiency as a function of the content and number of poisoned rods, is nearly linear [3,4]. Over the years, erbia has been used in a certain number of pressurized water reactors (PWRs) [5].

\footnotetext{
* e-mail: roberto.pergreffi@enea.it
}

Recently, increasing demands on the reduction of fuel cycle costs has led to higher burnup fuel designs. In UOxLWRs, extended burnups are achieved by higher initial uranium enrichment and consequently higher amounts of gadolinia. For this purpose, one of the main issues before very high assembly average burnups (>70 GWd/MTU) can be achieved is represented by the current enrichment limit for commercial-type LWR fuel, that is $5 \mathrm{wt} . \%$, due to criticality safety requirements related to the design of fabrication plants.

The erbia-credit super high burnup (Er-SHB) fuel concept developed a few years ago goes beyond the so called "5 wt.\% barrier" without requiring significant modifications and relicensing of fuel cycle facilities. The innovative idea is to mix low amount of erbia to $\mathrm{UO}_{2}$ powder directly after the reconversion process so that all fuel pins, in a given fuel assembly, are homogeneously doped [6,7]. In this way, notwithstanding the ${ }^{235} \mathrm{U}$ enrichment exceeds the current limit, the initial reactivity is equivalent to $\leq 5 \mathrm{wt} . \%$ fuel. It is worth noting that analyzing the multiplication factor of a fuel assembly enriched to $6 \mathrm{wt} . \%$ in ${ }^{235} \mathrm{U}$ with a poison content set to $0.2 \mathrm{wt} . \%$, it was found that gadolinia does not represent an alternative solution to erbia for such high burnup fuel concept because of a too large suppression of reactivity at beginning of life (BoL) due to its very large absorption cross section [7]. The Er-SHB fuel concept was not only studied from a neutronic viewpoint, in fact the effects of erbia addition on the thermal and mechanical properties of $\left(\mathrm{U}_{1-x} \mathrm{Er}_{x}\right) \mathrm{O}_{2}$ (with $0 \leq x \leq 0.1$ ) were measured [8]. 
The present work aims to characterize a $17 \times 17 \mathrm{PWR}$ assembly poisoned with erbia from a neutronic point of view comparing its neutronic performance to that of conventional $\mathrm{UO}_{2}$ fuel assembly enriched to $5 \mathrm{wt} . \%$ in ${ }^{235} \mathrm{U}$. According to Er-SHB fuel concept, erbium oxide is homogeneously dispersed into all fuel pins. More in detail, some crucial parameters of both fuel configurations such as multiplication factor, residual reactivity penalty, neutron spectrum, spectral index, boron reactivity worth and temperature reactivity coefficients were calculated at steady-state conditions. For this purpose, it was decided to use the APOLLO2 code that is recognized worldwide as a standard for deterministic cell calculations for LWRs. Moreover, a simplified thermal-hydraulic analysis was performed in order to evaluate the effects on fuel thermal conductivity of adding erbia to uranium oxide.

\section{Materials and methods}

\subsection{Geometry and material data}

The geometry adopted in this study corresponds to an $\mathrm{EPR}^{\mathrm{TM}}$ like assembly containing 265 fuel rods, each with an active length of $420 \mathrm{~cm}$, and 24 guide tubes. The fuel assembly is assumed to be composed of fuel cladding and moderator material only. Because no control rods have been taken into account, guide tubes have been filled with water (measurement and evaluation of the control rod worth is postponed to a future study). Helium into the gap between fuel and cladding has been neglected except for thermal-hydraulic analysis (see next paragraph). The water blade around the assembly is set to a value of $0.084 \mathrm{~cm}$. Dimensions of fuel, clad and guide tubes at room temperature are provided in Table 1.

The fuel is assumed to be pure $\mathrm{UO}_{2}$, only containing ${ }^{235} \mathrm{U}$ and ${ }^{238} \mathrm{U}$, mixed with small quantities of $\mathrm{Er}_{2} \mathrm{O}_{3}$; no ${ }^{234} \mathrm{U}$ was included, being considered negligible at first approximation for making comparisons between systems. Except for isocriticality curves that were drawn at varying ${ }^{235} \mathrm{U}$ enrichment and erbium content, for the rest of the analysis these values were fixed at $10.27 \mathrm{wt} . \%$ and 0.7038 wt.\% (=1 at.\%), respectively. If it is not differently specified, the boron concentration in the moderator is set to $1000 \mathrm{ppm}$ by mass (value for the BoC of the $\mathrm{EPR}^{\mathrm{TM}}$ first cycle). Cladding and guide tube are taken to be $\mathrm{M} 5{ }^{\circledR}$, a ternary alloy licensed by AREVA as fuel cladding material up to burnup values of $80 \mathrm{GWd} / \mathrm{MTU}$. In this study, M5 ${ }^{\circledR}$ was modeled as zirconium (98.875 wt.\%), niobium (1 wt.\%) and oxygen $(0.125 \mathrm{wt} . \%)$. The $\mathrm{M} 5^{\circledR}$ chemical composition at BoL at operating temperature is described in Table 2.

The presence of any structural materials (e.g., spacer grids) has been ignored.

The expanded dimensions of fuel, clad and guide tubes at operating temperatures have been obtained using linear thermal expansion coefficients. Value, reference temperature and source for each coefficient are detailed in Table 3.

Material densities at operating temperatures are provided in Table 4. In particular, pellet density depends on the content of erbia. As reported in [8], increasing the erbium content from 0 at. $\%$ to 5 at.\% the percentage of the theoretical density decreases going from $95 \%$ to $90 \%$.
Table 1. Fuel assembly geometry data.

\begin{tabular}{lll}
\hline Parameter & Unit & Value \\
\hline Assembly & & \\
Fuel assembly side & $\mathrm{cm}$ & 21.420 \\
Fuel assembly pitch & $\mathrm{cm}$ & 21.504 \\
Active length & $\mathrm{cm}$ & 420.00 \\
Pin configuration & - & $17 \times 17$ \\
No. fuel rods & - & 265 \\
No. guide tube positions & - & 24 \\
Fuel rods & & \\
Pin pitch & $\mathrm{cm}$ & 1.2627 \\
Outer clad radius & $\mathrm{cm}$ & 0.4750 \\
Inner clad radius & $\mathrm{cm}$ & 0.4180 \\
Outer pellet radius & $\mathrm{cm}$ & 0.4095 \\
Guide tubes & & \\
Outer diameter & $\mathrm{cm}$ & 0.6225 \\
Inner diameter & $\mathrm{cm}$ & 0.5725 \\
\hline
\end{tabular}

Table 2. Clad and guide tube composition.

\begin{tabular}{ll}
\hline $\mathrm{M}^{\circledR}{ }^{\circledR}$ chemical composition & Value $\left[\mathrm{at} / \mathrm{cm}^{3}\right]$ \\
\hline $\mathrm{Zr}[91.224]$ & $4.182 \mathrm{E}+22$ \\
$\mathrm{Nb}[92.906]$ & $4.153 \mathrm{E}+20$ \\
$\mathrm{O}[15.999]$ & $3.015 \mathrm{E}+20$ \\
\hline
\end{tabular}

Table 3. Linear thermal expansion coefficients.

\begin{tabular}{llrl}
\hline Material & $\begin{array}{l}\text { Linear thermal } \\
\text { expansion coefficient } \\
{\left[{ }^{\circ} \mathrm{C}^{-1}\right]}\end{array}$ & $T\left[{ }^{\circ} \mathrm{C}\right]$ & Source \\
\hline $\mathrm{UO}_{2}$ & $1.015 \mathrm{E}-05$ & 552 & {$[9]$} \\
$\left(\mathrm{U}_{1-x} \mathrm{Er}_{x}\right) \mathrm{O}_{2}$ & $1.150 \mathrm{E}-05$ & $50-1100$ & {$[8]$} \\
$\mathrm{M} 5^{\circledR}{ }^{\circledR}$ & $7.500 \mathrm{E}-06$ & 335 & {$[13]$} \\
\hline
\end{tabular}

Table 4. Densities of fuel, clad and moderator.

\begin{tabular}{lc}
\hline Material density & Value $\left[\mathrm{g} / \mathrm{cm}^{3}\right]$ \\
\hline $\mathrm{UO}_{2}$ & 10.245 \\
$\mathrm{Er}_{2} \mathrm{O}_{3}$ & 8.600 \\
$\left(\mathrm{U}_{0.99} \mathrm{Er}_{0.01}\right) \mathrm{O}_{2}$ & 9.696 \\
$\mathrm{M} 5^{\circledR 8}$ & 6.407 \\
$\mathrm{H}_{2} \mathrm{O}$ (without boric acid) & 0.702 \\
\hline
\end{tabular}

As almost all simulations refer to 1 at.\% Er-doped $\mathrm{UO}_{2}$ pellet, a percentage of the theoretical density of $94 \%$ was considered. In this case, the fuel density is $9.6955 \mathrm{~g} / \mathrm{cm}^{3}$. To calculate it, the fuel mass in one rod at room temperature 
Table 5. Average linear power density.

\begin{tabular}{lll}
\hline Parameter & Unit & Value \\
\hline $\begin{array}{l}\text { Average linear } \\
\text { power density }\end{array}$ & $\mathrm{MeV} / \mathrm{s} / \mathrm{cm}$ & $0.269649 \mathrm{E}+18$ \\
& $\mathrm{~W} / \mathrm{cm}$ & 163.40 \\
\hline
\end{tabular}

has been divided by the internal volume of the pin at operating temperature. The effect of boric acid on the moderator density has been neglected.

Table 5 shows the value of average linear power density required for the normalization of the neutron flux. This value has been computed multiplying the total core thermal power (4500 MWth) by the power percentage generated in the fuel (97.4\%) and dividing by the number of assemblies (241).

\subsection{Description of neutronic code}

All simulations were performed by means of the deterministic transport code APOLLO2 version 2.8-3.E [10]. APOLLO2 is a modular cell code for 2-dimensional multigroup transport calculations. Microscopic cross sections refer to 281 groups' master library with a SHEM group structure CEA2005V4.1.2.patch, based on JEFF 3.1.1 evaluations. Calculations were done assuming reflective boundary conditions and taking advantage of all symmetries of the system, so that only $1 / 8$ of assembly was considered. A schematic of $1 / 8$ of modeled assembly is given in Figure 1. Elementary fuel cell was divided into four concentric zones corresponding, from center to periphery, to $50 \%, 30 \%, 15 \%$, and $5 \%$ of the total volume, respectively, one clad zone and one moderator zone (the search for an optimized number of fuel regions to rigorously take into account the rim effect for erbia is postponed for a future study). The elementary guide tube cell was modeled in two moderator zones, divided by the guide tube. Collision Probability method was used in APOLLO2 to resolve the transport equation to compute the neutron flux. Self-shielding calculations were done bearing in mind the following order of isotopes: ${ }^{238} \mathrm{U},{ }^{235} \mathrm{U},{ }^{167} \mathrm{Er},{ }^{239} \mathrm{Pu},{ }^{240} \mathrm{Pu}$, $\mathrm{Zr}$ nat. TR (all resonances) approximation was used over the entire energy range. The effect of leakage on the neutron spectrum was taken into account by means of homogenous B1 model that computes the buckling to assure criticality.

\section{Thermal-hydraulic analysis}

The purpose of the analysis is to calculate the impact on PWR fuel pin temperature distribution due to erbia poisoning. Therefore, a pin containing 1 at.\% of erbia and enriched to $10.27 \%$ in ${ }^{235} \mathrm{U}$ was compared with a reference case with enrichment of $5 \%$ and no poisoning. From a preliminary qualitative analysis, two main antagonistic effects are foreseen which are as follows:

- reduction of fuel conductivity in the poisoned pin is expected to cause a rise in centerline fuel temperature;

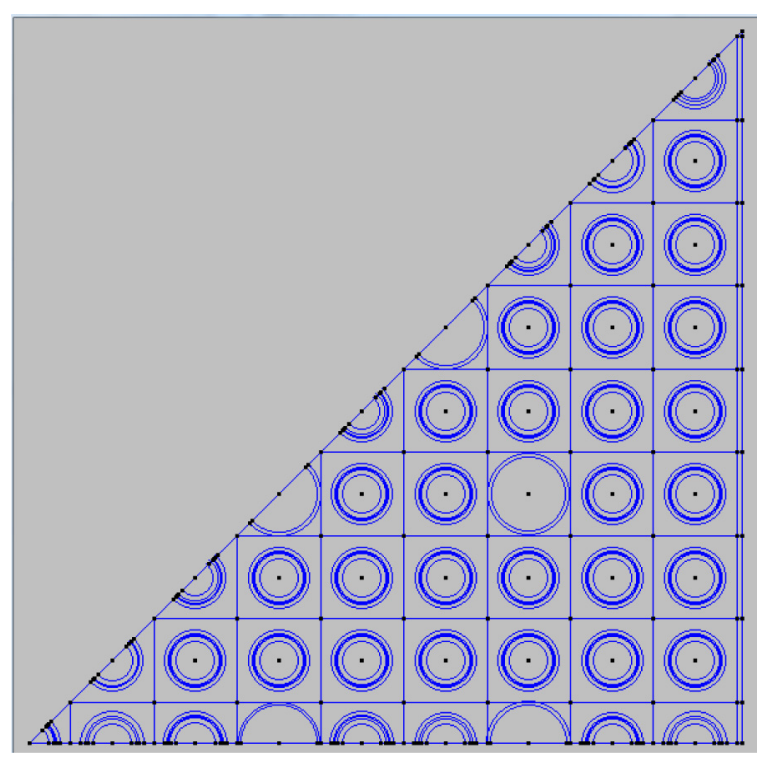

Fig. 1. Model of $1 / 8$ of the fuel assembly.

Table 6. Thermal-hydraulic data.

\begin{tabular}{lll}
\hline Parameter & Unit & Value \\
\hline Cold fuel-clad gap & $\mathrm{cm}$ & $8.50 \mathrm{E}-03$ \\
Coolant flow area & $\mathrm{cm}^{2}$ & $5.66 \mathrm{E}+04$ \\
Wet perimeter & $\mathrm{cm}$ & $1.906 \mathrm{E}+5$ \\
Hydraulic diameter & $\mathrm{cm}$ & 1 \\
Coolant mass flow & $\mathrm{kg} / \mathrm{s}$ & 20,135 \\
Coolant pressure & $\mathrm{bar}$ & 155 \\
Bulk temperature (average in core) & ${ }^{\circ} \mathrm{C}$ & 314 \\
\hline
\end{tabular}

- increase in neutron absorption in the peripheral area of the pellet due to the presence of erbia and to the higher fissile concentrations is expected to cause an increase in centre pellet flux depression with consequent decrease of centerline fuel temperature.

The thermal-hydraulic analysis was based on the data from an EPR ${ }^{\mathrm{TM}}$ pre-construction safety report [11]. Some thermal-hydraulic parameters are described in Table 6 .

The analysis was carried out at BoL. The power to be transferred from the fuel rods to the coolant was calculated as described in previous paragraph. No hottest pin analysis was necessary because the neutronic calculations were performed, as usual, using reflective boundary conditions; therefore, no difference of flux and, consequently, of power is possible with only one type of fuel pins in the assembly.

Heat transfer from the pins to the coolant is a typical case of convection involving heat transfer between a surface and an adjacent fluid at different temperatures. The dominant contribution to such heat transfer is the bulk motion of fluid, with a minor contribution by conduction. The convective heat flux is modeled by Newton's law of cooling, with all the variations due to fluid properties, 
surface geometry and flow conditions included in the convection coefficient $h_{w}$ :

$$
T_{\mathrm{we}}=T_{B}+\frac{q^{\prime}}{\pi D h_{w}},
$$

where $T_{\text {we }}$ is the external clad temperature, $T_{B}$ the bulk temperature (averaged over the core), $q^{\prime}$ the average linear power, and $D$ the sub-channel hydraulic diameter.

The convection coefficient depends upon many variables; the approach to its determination consists in identifying universal functions of dimensionless groups with physical meaning for convective flow. The Nusselt number $\mathrm{Nu}=h L / k$, where $L$ and $k$ represent the characteristic length of the surface and the thermal conductivity, respectively, physically represents the dimensionless temperature gradient at the surface. In forced convection $\mathrm{Nu}$ can be correlated with the Reynolds number $\operatorname{Re}=\rho v L / \mu$, physically representing the ratio of inertia and viscous forces, and the Prandtl number $\operatorname{Pr}=c_{p} \mu / k$, representing the ratio of the momentum and thermal diffusivity. In water cooled reactors for purely single phase flow, the Nusselt number can be evaluated by employing the Dittus-Boelter correlation:

$$
\mathrm{Nu}=0.023 \times \operatorname{Re}^{0.8} \times \operatorname{Pr}^{0.4} .
$$

All the physical properties and correlations for water were derived by interpolating the data from NIST standard reference data. In the case considered $\mathrm{Nu}$ has a value of 844 and consequently $h_{w}=37,157 \mathrm{~W} /\left(\mathrm{m}^{2} \mathrm{~K}\right)$. The external cladding temperature results $T_{\mathrm{we}}=325^{\circ} \mathrm{C}$.

Heat transfer through the cladding material was modeled by the steady state heat conduction equation reduced to a one-dimensional equation in the radial direction in absence of heat generation. After integration the equation becomes:

$$
T_{\text {wi }}=T_{\text {we }}+\frac{q^{\prime} t_{c}}{\pi D k_{c}},
$$

where $t_{c}$ is the cladding material thickness $\left(\mathrm{M} 5^{\circledR}\right)$. The conductivity of $\mathrm{M} 5^{\circledR}$ was taken from [12] and set to the value of $k_{c}=18 \mathrm{~W} /(\mathrm{m} \mathrm{K})$. The internal cladding temperature was found to be $T_{\mathrm{wi}}=344^{\circ} \mathrm{C}$.

Heat transfer through the gap was modeled through the standard general equation:

$$
T_{\mathrm{ps}}=T_{\mathrm{wi}}+\frac{q^{\prime}}{\pi D h_{G}} .
$$

According to the Ross-Staute gap conductance model, reported in [13], the gap conductance $h_{G}$ was calculated as:

$$
h_{G}=\frac{k_{G}}{G},
$$

where $k_{G}$ is the thermal conductivity of the gap gas (pure helium at the beginning of cycle) and $G$ is the gap thickness at the beginning of cycle. At the beginning of cycle the effects of burnup on the pellet are not detectable yet, but the pellet expansion can't be calculated as simple thermal expansion because, as soon as the reactor power increases, pellets crack due to thermal stress induced by radial temperature gradients [13]. This phenomenon causes an increase of the apparent pellet diameter and consequently a significant gap reduction. This gap thickness at the beginning of cycle during irradiation was calculated by application of the model proposed by Oguma [13] as

$$
G=\left(G_{0}-0.0036 D\right) e^{\left[-0.0039 \times\left(q^{\prime}-60\right)\right]} \quad[\mu \mathrm{m}],
$$

where $G$ is the gap of the beginning of cycle full power pin, $G_{0}$ is the initial as-fabricated gap, $D$ is the pellet diameter all in microns and $q^{\prime}$ is the linear power in $\mathrm{W} / \mathrm{cm}$. In such model, the experimental constants were derived from in pile gap analyses of instrumented fuel rods irradiated in a boiling water reactor (BWR). Therefore, to apply this model to a PWR, a correction was introduced to take into account the difference in coolant pressure and its effect on elastic deformations of the cladding material. The correction was calculated using, for the calculation of the Young modulus of Zircaloy, the MATPRO formula [12]:

$$
Y[\mathrm{~Pa}]=\frac{\left(1.088 \times 10^{11}-5.475 \times 10^{7} \times T+K_{1}+K_{2}\right)}{K_{3}},
$$

by neglecting the modifications due to the effect of oxidation $\left(K_{1}=0\right)$ and the effect of fast neutron fluence $\left(K_{3}=1\right)$ and calculating the modification to account for the effect of cold work (the fractional reduction in cross-section area due to processing) as:

$$
K_{2}[\mathrm{~Pa}]=2.6 \times 10^{10} \times C,
$$

with the cold work assumed as $C=0.2$ (default value of FRAPCON code) [14]. The pellet surface temperature determined this way was $T_{\mathrm{ps}}=453^{\circ} \mathrm{C}$.

Heat transfer through the fuel was modeled by the steady state heat conduction equation reduced to a onedimensional equation in the radial direction:

$$
\frac{1}{r} \frac{d}{d r}\left(k_{f} r \frac{d T}{d r}\right)+q^{\prime \prime \prime}=0,
$$

where $q^{\prime \prime}$ is the power density generated by the nuclear reactions within the fuel. For the solution, the $q^{\prime \prime}$ radial distribution needs to be known. This distribution can be obtained by parabolic interpolation of power densities calculated by APOLLO2 in ten different concentric fuel regions, but a value of the effective fuel temperature $T_{\text {eff }}$ is required by APOLLO2 for effective cross sections determination. To provide a first attempt value of $T_{\text {eff }}$, the maximum centerline temperature $T_{\mathrm{pc}}$ was assumed to have the value resulting by solving the heat equation in the assumption of a radially constant $q^{\prime \prime}$. This first attempt value of $T_{\text {eff }}$ was calculated as follows [15]:

$$
T_{\text {eff }}=0.3 \times T_{\mathrm{pc}}+0.7 \times T_{\mathrm{ps}} .
$$


With this value of $T_{\text {eff }}$ a first attempt neutronic simulation was run to obtain a first attempt power distribution. These results were interpolated by a curve in the form:

$$
q^{\prime \prime \prime}=a \times r^{2}+c .
$$

Such expression was introduced in (9). After integration and separation of variables and considering that the minimum fuel temperature is reached on the pellet surface $T_{\mathrm{ps}}$ and the maximum in the centerline $T_{\mathrm{pc}}$, the heat equation becomes:

$$
\int_{T_{\mathrm{ps}}}^{T_{\mathrm{pc}}} k_{f}(T) d T=a \frac{R^{4}}{16}+c \frac{R^{2}}{4}
$$

where $T_{\mathrm{pc}}$ is the unknown value to be found, and $R$ is the fuel pin radius whose thermal expansion was calculated by the following correlation [16]:

$$
\begin{aligned}
\frac{\Delta R}{R} & =9.8 \times 10^{-06} T-2.61 \times 10^{-03} \\
& +3.16 \times 10^{-01} \times \exp \left(\frac{-1.32 \times 10^{-19}}{1.38 \times 10^{-23} T}\right) .
\end{aligned}
$$

Every time a new value of $T_{\text {eff }}$ was calculated, $R\left(T_{\text {eff }}\right)$ was updated. According to [8], the temperature dependence of the thermal conductivity of erbia enriched uranium dioxide $\left(\mathrm{U}_{1-x} \mathrm{Er}_{x}\right) \mathrm{O}_{2}$ as a function of Er content, $x$ is:

$$
\begin{aligned}
k_{f}[\mathrm{~W} /(\mathrm{m} \mathrm{K})]= & \frac{1}{6.44 \times 10^{-2}+1.02 \times x+(1.55-4.63 \times x) \times 10^{-4} \times T} \\
& (0 \leq x \leq 0.1 ; 298 \mathrm{~K} \leq T \leq 1473 \mathrm{~K}), \quad(14)
\end{aligned}
$$

after substituting and integrating over $T$, the centerline temperature $T_{\mathrm{pc}}$ could be determined in the cases of $x=0$ and $x=0.01$ (i.e. 1 at.\% of erbia). With this temperature a second attempt value of $T_{\text {eff }}$ was calculated as before and a second more accurate neutronic simulation was carried out. The procedure was iterated until convergence was reached; starting with the value of $T_{\text {eff }}$ calculated assuming a radially constant $q^{\prime \prime}$, convergence to within $\pm 0.1^{\circ} \mathrm{C}$ was reached with three iterations.

In the poisoned pin the power distribution showed a slightly higher variation between the peripheral area and the pellet center with respect to the reference case. The power calculated for the outermost of the ten regions considered in the simulation resulted $4 \%$ higher than the reference case, while in the inner region it was $3 \%$ lower. Consequently, the last iteration values of the parabolic interpolation coefficients of the power distribution were $a=2.39 \times 10^{12} \mathrm{~W} / \mathrm{cm}^{5}$ and $c=2.85$ $\times 10^{8} \mathrm{~W} / \mathrm{cm}^{3}$ for the reference case and $a=3.74 \times 10^{12}$ $\mathrm{W} / \mathrm{cm}^{5}$ and $c=2.74 \times 10^{8} \mathrm{~W} / \mathrm{cm}^{3}$ for the erbia poisoned pin. The two values of maximum centerline temperatures were as follows:

- $T_{\mathrm{pc}}=740^{\circ} \mathrm{C}$ for the reference case with $x=0$,

$-T_{\mathrm{pc}}=744^{\circ} \mathrm{C}$ for the poisoned pin with $x=0.01$.

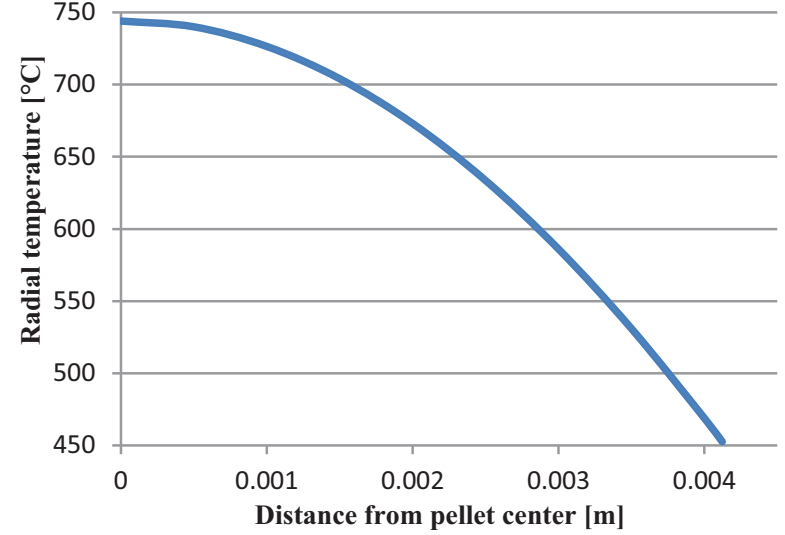

Fig. 2. Radial temperature profile of the erbia enriched fuel pellet.

Table 7. Temperatures of pellet, clad and moderator.

\begin{tabular}{ll}
\hline Temperature & Value $\left[{ }^{\circ} \mathrm{C}\right]$ \\
\hline Fuel centerline temperature & 744 \\
Fuel surface temperature & 453 \\
Effective fuel temperature & 540 \\
Internal clad temperature & 344 \\
External clad temperature & 325 \\
Average clad temperature & 335 \\
Moderator and guide tube temperature & 314 \\
\hline
\end{tabular}

The increase in temperature is very limited given the small decrease $(-3 \%)$ of the conductivity of the poisoned fuel at the higher enrichment. This effect is further alleviated by the more favorable power distribution, characterized by a lower power generation in the inner regions where the heat produced is more difficult to dispose of. The radial temperature profile of the erbia enriched fuel pellet is plotted in Figure 2.

All relevant temperatures used for the neutronics analysis described in the next paragraph are summarized in Table 7.

\section{Neutronic analysis}

The main results of the neutronics characterization of a (U, Er) $\mathrm{O}_{2}$ fuel assembly are presented below.

First of all, three isocriticality curves at BoL related to three different boron concentrations are plotted in Figure 3. Each curve correlates the erbium content with the uranium enrichment so that the multiplication factor of the $\left(\mathrm{U}_{1-x} \mathrm{Er}_{x}\right) \mathrm{O}_{2}$ fuel is equivalent (difference less than $\pm 5 \mathrm{ppm}$ ) to that of the corresponding $\mathrm{UO}_{2}$ fuel (i.e. enriched to $5 \mathrm{wt} . \%$ in ${ }^{235} \mathrm{U}$ ). It is worth noting that, increasing the boron concentration, the erbium content required to compensate the initial excess reactivity increases. This means that the negative reactivity worth of erbium is partially reduced by that of boron. 
Table 8. Fuel configurations.

\begin{tabular}{ll}
\hline Configuration & Fuel description \\
\hline Reference case & $\mathrm{UO}_{2}$ fuel enriched to 5 wt.\% in ${ }^{235} \mathrm{U}$ \\
Case-1 & $\mathrm{UO}_{2}$ fuel enriched to $10.27 \mathrm{wt.} \%$ in ${ }^{235} \mathrm{U}$ \\
Case-2 & $\left(\mathrm{U} \mathrm{Er}_{2} \mathrm{O}_{2}\right.$ fuel enriched to $10.27 \mathrm{wt} . \%$ \\
& in ${ }^{235} \mathrm{U}$ and with an erbia content \\
& of 1 at.\% \\
\hline
\end{tabular}

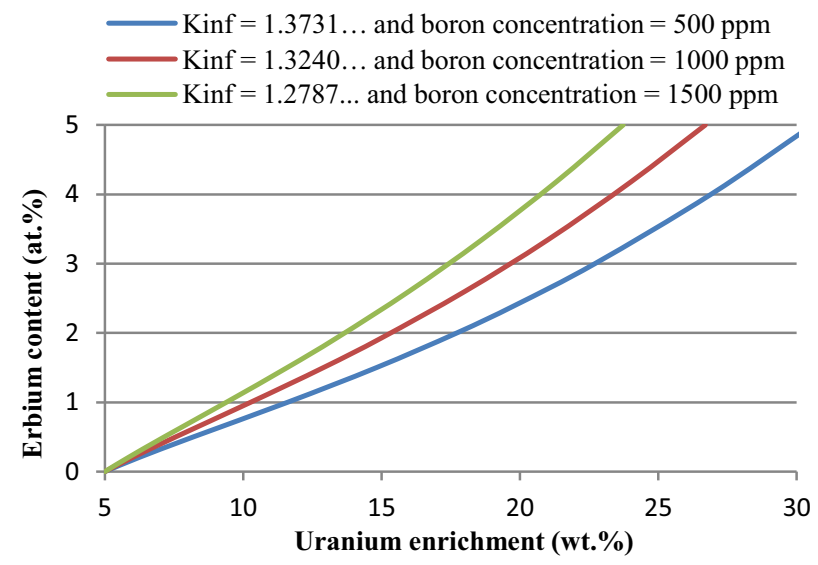

Fig. 3. Isocriticality curves at BoL.

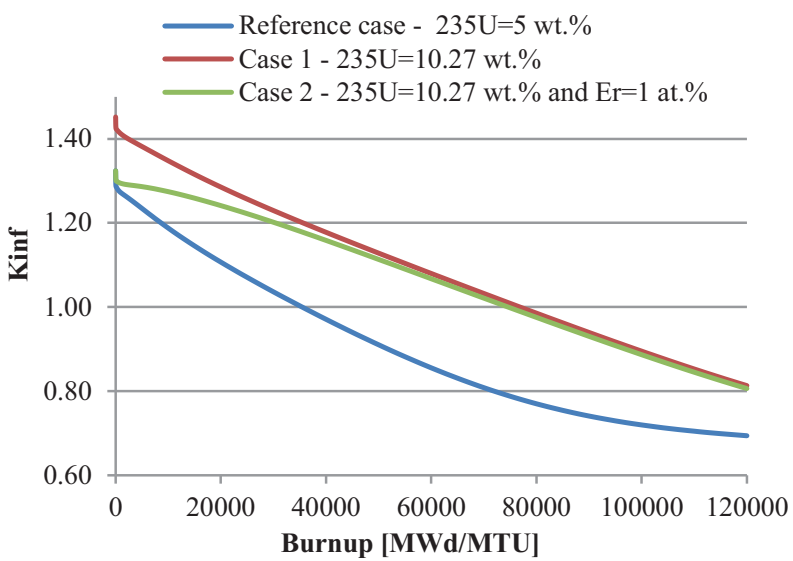

Fig. 4. Multiplication factor vs. burnup.

In order to make the interpretation of the following results easier, the three considered fuel configurations have been summarized in Table 8 . The choice of a $\mathrm{UO}_{2}$ fuel enriched to $5 \mathrm{wt} . \%$ in ${ }^{235} \mathrm{U}$ as Reference case depends on the fact that this enrichment represents a superior limit for the commercial-type power reactors.

The increase of initial ${ }^{235} \mathrm{U}$ enrichment beyond the " 5 wt.\% barrier" requires an accurate assessment of criticality implications. This includes verifying that the positive extra-reactivity due to higher enrichment is controlled by the negative reactivity due to erbia at every burnup step. Figure 4 shows the infinite neutron multiplication factor as a function of burnup of the three

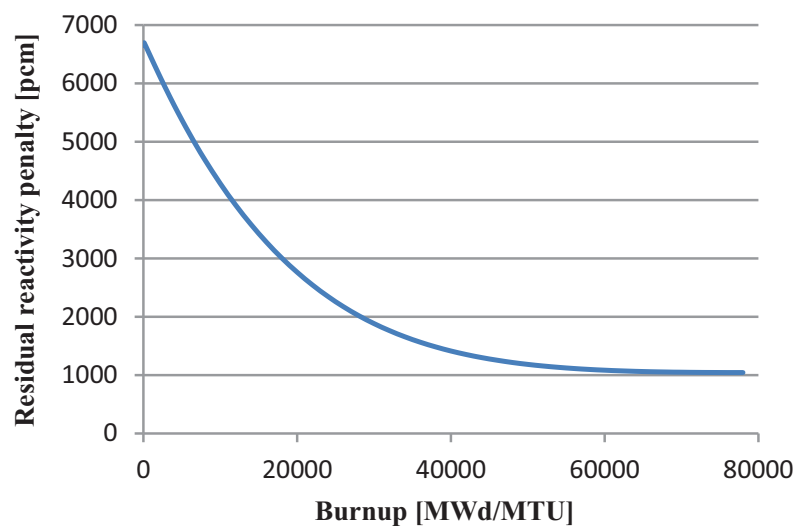

Fig. 5. Residual reactivity penalty.

different configurations. As it can be noted, Case-2 has the same criticality at BoL of Reference case ( $5 \mathrm{wt} . \%$ fuel) but, differently from this, it achieves $k=1$ when the burnup value is about $76 \mathrm{GWd} / \mathrm{MTU}$. The fact that, notwithstanding the initial enrichment of Case-2 is to $10.27 \mathrm{wt} . \%$, its initial criticality does not exceed the maximum criticality value of the Reference case (1.32400 vs. 1.32402 ), is a remarkable aspect from a safety point of view. It is also noteworthy to observe the fact that the reduction of initial reactivity of Case-2 with respect to Case-1 (1.32400 vs. 1.45179) is completely due to the erbia content. Furthermore, the burnup for which $k=1$ is quite similar to the value indicated in some studies as optimal point in terms of generation cost for a conventional PWR with $>5$ wt.\% uranium enrichment level $[17,18]$.

The effects of erbia on the assembly reactivity can also be taken into account in terms of residual reactivity penalty. The reactivity penalty is defined as the difference of reactivity between Case- 1 and Case-2, i.e. between two different fuels both enriched to $10.27 \mathrm{wt} . \%$ in ${ }^{235} \mathrm{U}$ with and without erbium oxide. As plotted in Figure 5, the residual reactivity penalty decreases with increasing burnup and it is of about $1000 \mathrm{pcm}$ when the burnup exceeds $76 \mathrm{GWd} /$ MTU. As suggested in [6], the residual penalty could be removed by modifying erbium isotopically, i.e. eliminating ${ }^{166} \mathrm{Er}$. In fact the residual reactivity penalty at end of life $(\mathrm{EoL})$ is mainly due to the presence of ${ }^{167} \mathrm{Er}$ isotope which is built up from ${ }^{166} \mathrm{Er}$. This fact is confirmed by ${ }^{167} \mathrm{Er}$ and ${ }^{166} \mathrm{Er}$ concentrations as a function of burnup plotted in Figure 6. In addition, if the ${ }^{167} \mathrm{Er}$ concentration significantly lessens in the first part of the curve as a result of its absorption macroscopic cross section, it is substantially constant over time starting from a burnup value of about $40 \mathrm{GWd} / \mathrm{MTU}$.

Another relevant neutronic aspect is related to the production of ${ }^{239} \mathrm{Pu}$. The concentration of ${ }^{239} \mathrm{Pu}$ as a function of burnup is plotted in Figure 7 with reference to the two fuel configurations: Reference case (curve in blue) and Case-2 (curve in red).

This concentration expresses the balance between production and destruction of ${ }^{239} \mathrm{Pu}$ instant by instant. It is well known that:

$-{ }^{239} \mathrm{Pu}$ production is roughly proportional to fast flux and ${ }^{238} \mathrm{U}$ effective macroscopic cross section; 


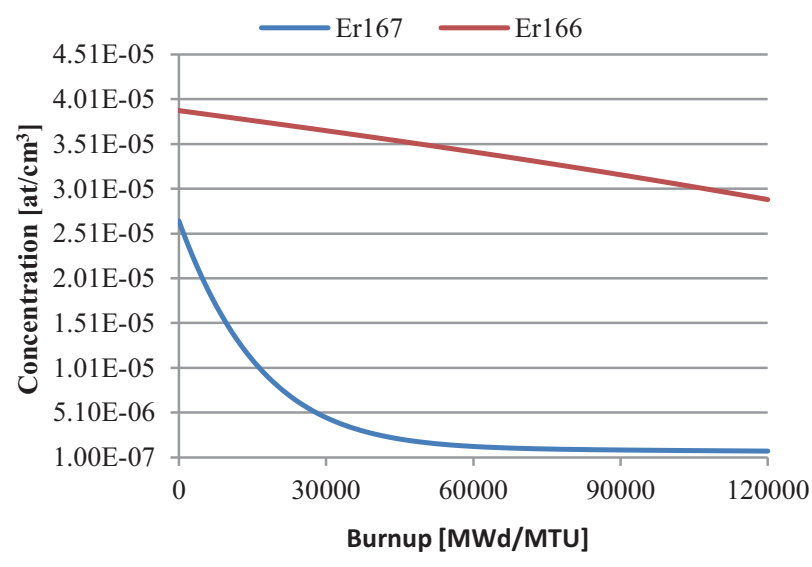

Fig. 6. ${ }^{167} \operatorname{Er}$ and ${ }^{166} \operatorname{Er}$ concentrations vs. burnup.

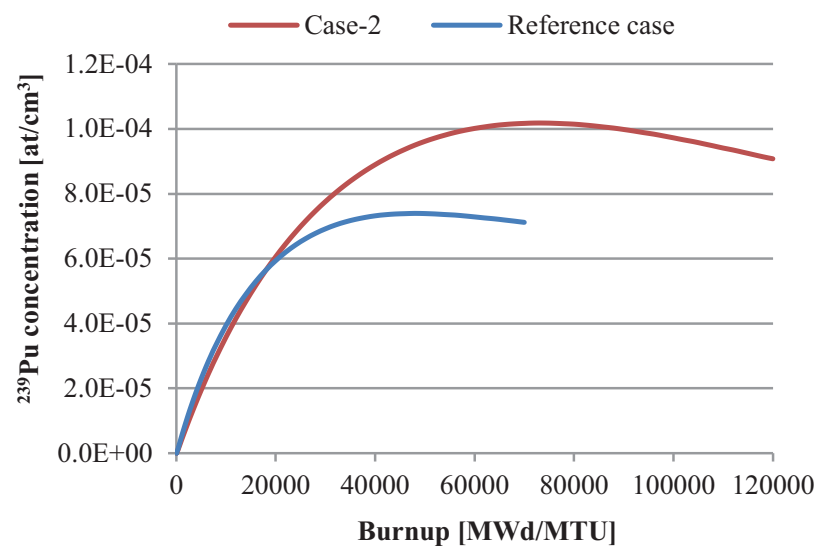

Fig. 7. Burnup varying ${ }^{239} \mathrm{Pu}$ concentration.

$-{ }^{239} \mathrm{Pu}$ destruction is roughly proportional to thermal flux and ${ }^{239} \mathrm{Pu}$ effective macroscopic cross section.

Therefore, denoting the production and destruction terms as:

$$
\begin{aligned}
& P \cong \Sigma_{\text {eff }}^{c}(\mathrm{U} 238) \times \phi_{\text {fast }}, \\
& D \cong \Sigma_{\text {eff }}^{a}(\mathrm{Pu} 239) \times \phi_{\mathrm{th}},
\end{aligned}
$$

and analyzing the two curves in Figure 7, we can observe that these two terms in the two configurations are very similar up to a burnup value of about $20 \mathrm{GWd} / \mathrm{MTU}$. In other words the following relation can be written as:

$$
(P-D)_{\text {Case-2 }} \cong(P-D)_{\text {Reference case }} .
$$

It is however important to underline that the equivalence of the differences in the two cases does not imply the equivalence term to term. On the contrary, analyzing the data in Tables 9 and 10 it can clearly be seen that ${ }^{238} \mathrm{U}$ concentration as well as the fast and thermal fluxes at BoL are very different in the two configurations. In addition, easy physical considerations permit to extend the same conclusion also to the effective microscopic cross sections of
Table 9. ${ }^{235} \mathrm{U}$ and ${ }^{238} \mathrm{U}$ concentrations at BoL.

\begin{tabular}{lcc}
\hline Assembly configuration & ${ }^{235} \mathrm{U}\left[\mathrm{at} / \mathrm{cm}^{3}\right]$ & ${ }^{238} \mathrm{U}\left[\mathrm{at} / \mathrm{cm}^{3}\right]$ \\
\hline Reference case & $1.176 \mathrm{E}+21$ & $2.206 \mathrm{E}+22$ \\
Case-2 & $2.342 \mathrm{E}+21$ & $2.025 \mathrm{E}+22$ \\
\hline
\end{tabular}

uranium and plutonium. Between $20 \mathrm{GWd} / \mathrm{MTU}$ and $76 \mathrm{GWd} / \mathrm{MTU},{ }^{239} \mathrm{Pu}$ concentration of Case-2 builds up differently from the Reference case. This fact means that in the assembly with lower enrichment in ${ }^{235} \mathrm{U},{ }^{239} \mathrm{Pu}$ reaches equilibrium at a much lower burnup value because of its more important contribution to the total power produced.

In Figure 8, the normalized fluxes per unit lethargy at $0 \mathrm{GWd} / \mathrm{MTU}$ of both configurations are plotted. As it can clearly be seen, the flux of the assembly poisoned with erbia is less thermalized than the other. In fact, the increased thermal neutron absorption due to erbium causes a hardening of the flux. This effect is confirmed by analyzing the spectral index values at different burnup steps in Table 10. The spectral index, which is defined here as the ratio between fast and thermal flux, is always higher in the Er-doped assembly, owing to the increased thermal neutron absorption or, similarly, to the larger amount of absorbers at thermal energy in that assembly. But, if each single term is analyzed, an opposite trend can be observed: at each burnup step, both the fast flux and the thermal flux are larger in the reference assembly than in the assembly poisoned with erbia. After all, even if the neutron flux is less hardened at low enrichment, the total flux has to be bigger in order to produce the same power.

In Figure 9, the evolution of the flux per unit lethargy of Case-2 configuration is plotted with reference to four different burnup values. As a rule, in order to produce the same power, the total flux has to increase because of the reduction of fissile material. It is interesting to observe that, while going from low to high burnup values, the thermal part of the flux is progressively more relevant. In addition, the dip at thermal energies $(\sim 1 \mathrm{eV})$ due to ${ }^{239} \mathrm{Pu}$ resonances can clearly be seen.

The reactivity worth of $1 \mathrm{ppm}$ of boron according to the following definition:

$$
w_{B}=\frac{\Delta k}{\Delta c_{B}}=\frac{k\left(c_{B}=1010\right)-k\left(c_{B}=1000\right)}{10},
$$

where $w_{B}$ is the boron worth, $k$ is the multiplication factor, and $c_{B}$ is the boron concentration, is plotted in Figure 10 as a function of burnup. This graph refers to the assembly enriched to $10.27 \mathrm{wt} . \%$ in ${ }^{235} \mathrm{U}$ and poisoned with erbia. The boron reactivity worth has a moderate variation over time up to a burnup value of about $65 \mathrm{GWd} / \mathrm{MTU}$. In fact after a rapid reduction due to the xenon and samarium poisoning, the boron worth goes from a value of about $5 \mathrm{pcm} / \mathrm{ppm}$ to a value of $4.5 \mathrm{pcm} / \mathrm{ppm}$ as a result of the spectrum hardening due to the plutonium build-up.

In terms of boron controlled reactivity, no differences arise with respect to a standard PWR, given the fact that $k_{\infty}$ at BoL is the same for the two systems. However, the Er-doped fuel assembly needs almost twice boric acid to 
Table 10. Spectral index.

\begin{tabular}{lcccc}
\hline & $\mathrm{BU}=0$ & $\mathrm{BU}=30,000$ & $\mathrm{BU}=70,000$ & $\mathrm{BU}=120,000$ \\
\hline${ }^{235} \mathrm{U}=10.27$ wt.\% and $\mathrm{Er}=1$ at.\% (Case-2) & & & \\
Fast flux & $9.40 \mathrm{E}+16$ & $1.04 \mathrm{E}+17$ & $1.22 \mathrm{E}+17$ & $1.52 \mathrm{E}+17$ \\
Thermal flux & $3.27 \mathrm{E}+16$ & $3.62 \mathrm{E}+16$ & $4.39 \mathrm{E}+16$ & $5.92 \mathrm{E}+16$ \\
Total flux & $1.27 \mathrm{E}+17$ & $1.41 \mathrm{E}+17$ & $1.66 \mathrm{E}+17$ & $2.11 \mathrm{E}+17$ \\
Spectral index & 2.88 & 2.88 & & 2.78 \\
$235 U=5$ wt.\% (Reference case) & & & $1.55 \mathrm{E}+17$ \\
Fast flux & $9.87 \mathrm{E}+16$ & $1.24 \mathrm{E}+17$ & $7.01 \mathrm{E}+16$ & $8.08 \mathrm{E}+16$ \\
Thermal flux & $4.48 \mathrm{E}+16$ & $5.38 \mathrm{E}+16$ & $2.25 \mathrm{E}+17$ & $2.58 \mathrm{E}+17$ \\
Total flux & $1.43 \mathrm{E}+17$ & $1.78 \mathrm{E}+17$ & 2.21 & 2.19 \\
Spectral index & 2.20 & 2.31 & & \\
\hline
\end{tabular}

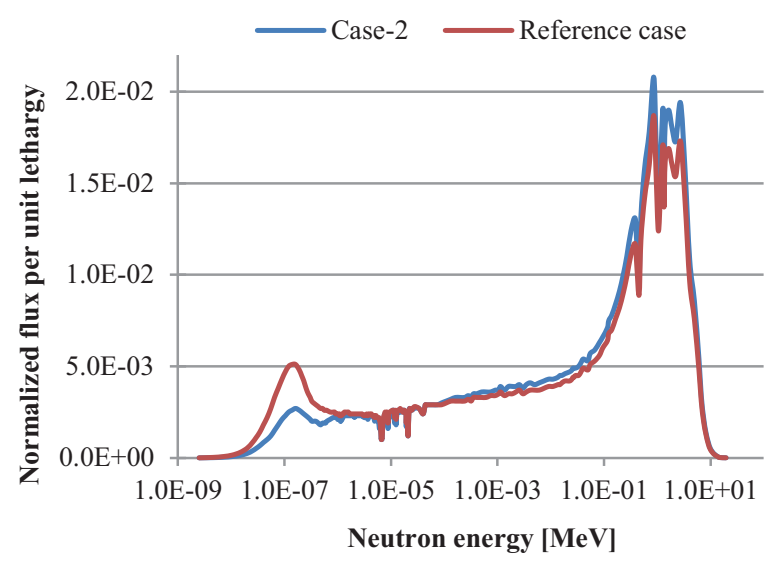

Fig. 8. Normalized flux per unit lethargy.

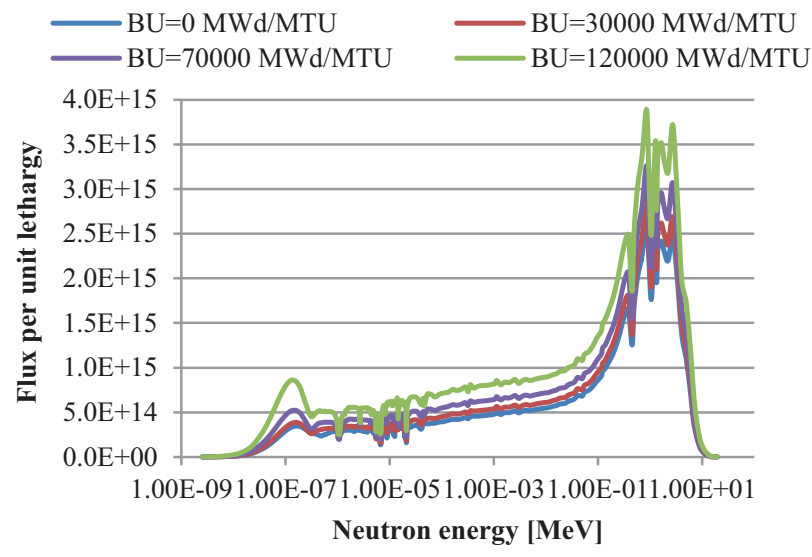

Fig. 9. Flux per unit lethargy.

achieve the same reactivity value. In fact the boron reactivity worth of Case-2 is about half that of Reference case, even if initial concentration values are the same $(1000 \mathrm{ppm})$. This fact may have some drawbacks as far as the primary coolant chemistry is concerned; the analysis of this aspect is however out of the scope of the present paper.

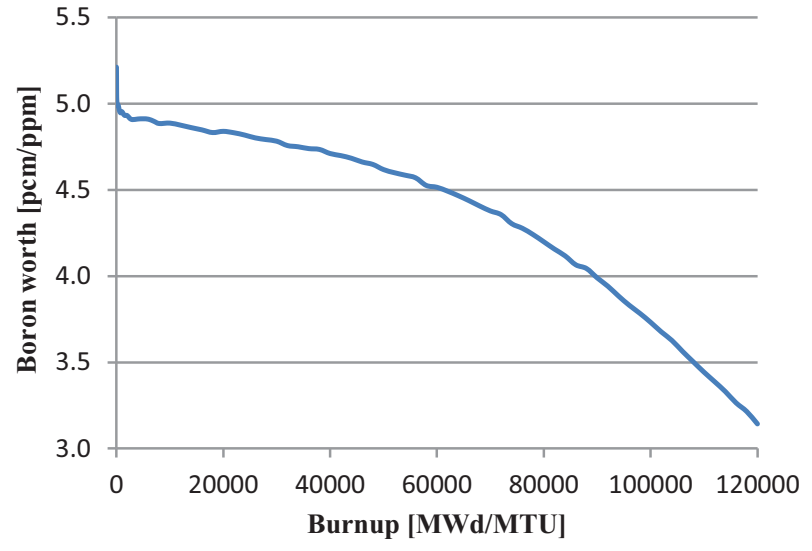

Fig. 10. Boron worth as a function of burnup.

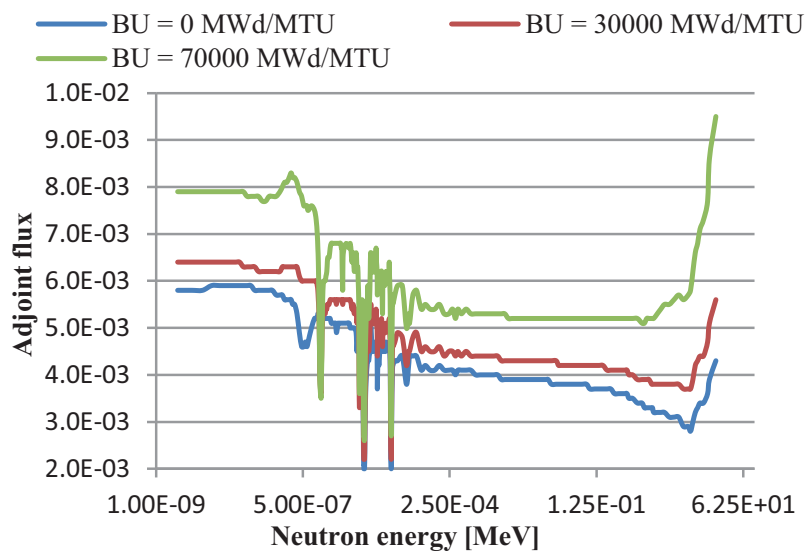

Fig. 11. Normalized adjoint neutron fluxes.

One of the most important aspects of the fission process from the reactor control viewpoint, is the presence of effective delayed neutrons. The effective delayed neutron fraction $-\beta_{\text {eff }}-$ is calculated weighting delayed neutrons on the adjoint neutron flux. For this purpose, adjoint flux calculations were performed together with direct flux calculations at each burnup step. In Figure 11, three 


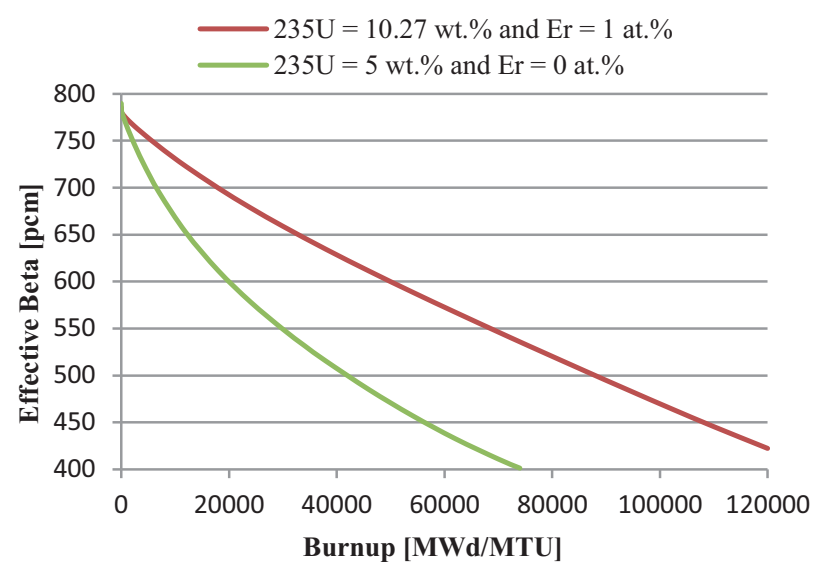

Fig. 12. Burnup varying effective beta for two fuel configurations.

examples of normalized adjoint neutron flux at three different burnup values have been plotted. The effects of ${ }^{239} \mathrm{Pu}$ resonances are very well shown in the two curves corresponding to burnup values of 30 and $70 \mathrm{GWd} / \mathrm{MTU}$.

$\beta_{\text {eff }}$ as a function of burnup with reference to two fuel configurations is shown in Figure 12. All calculations were performed with APOLLO2 considering production and decay of eight groups of delayed neutron precursors. In both curves, increasing the burnup value, the effective beta decreases, going from about 800 to about $400 \mathrm{pcm}$ as a result of the ${ }^{239} \mathrm{Pu}$ build-up and ${ }^{235} \mathrm{U}$ depletion. But the effective beta of the assembly poisoned with erbia decreases more slightly than the Reference case.

Temperature reactivity coefficients are crucial parameters in transients of LWRs. As the temperature does not change uniformly throughout the assembly, two different temperature reactivity coefficients related fuel and moderator were calculated:

- fuel temperature coefficient (FTC), denoted as $\alpha_{\text {Dop }}$ and defined as the fractional change in $k$ per unit change in effective fuel temperature;

- moderator temperature coefficient (MTC), denoted as $\alpha_{\text {Mod }}$ and defined as the fractional change in $k$ per unit change in moderator temperature considering a change in water density [19].

All temperature reactivity coefficients have been computed according to the following relation [20]:

$$
\alpha_{T}=\frac{\Delta \rho}{\Delta T}=\frac{\left(k_{f}-k_{i}\right) /\left(k_{f} \times k_{i}\right)}{\Delta T},
$$

where $\rho$ is the reactivity, $k_{i}$ and $k_{f}$ are the initial and final multiplication factors, and $T$ is the temperature.

The FTC for Er-doped assembly, in going from initial effective fuel temperature $\left(540^{\circ} \mathrm{C}\right)$ to final temperatures, produces a reactivity change very similar to other fuels and in particular to the Reference case, as shown in Table 11. Considering that all calculations were performed at zero burnup, the largest contribution to the FTC is due to the increase in resonant capture by
${ }^{238} \mathrm{U}$. Nevertheless, the ${ }^{167} \mathrm{Er}$ and ${ }^{166} \mathrm{Er}$ contribution in Er-doped assembly is not negligible. In particular, the positive contribution of the erbium isotopes to the FTC can be appreciated by comparing the two configurations enriched to $10.27 \mathrm{wt} . \%$ in ${ }^{235} \mathrm{U}$.

The same reasoning can be extended to the MTC (Tab. 12). In this case too, a change of temperature causes a change of the opposite sign in the reactivity. In addition, in going from initial effective moderator temperature $\left(314^{\circ} \mathrm{C}\right)$ to final temperatures, the reactivity of the Er-doped assembly changes much more than those of the other fuels also including the Reference case. As the temperature effect on reactivity is due to moderator density change, Table 13 summarizes water density values used for MTC calculations. It is worth noting that the water density depends only on temperature (i.e., the effect of boric acid concentration on water density was neglected) [21].

It can be concluded that the performance of Er-doped assembly from the safety viewpoint is at least as good as that of the Reference case, i.e., of $\mathrm{UO}_{2}$ fuel enriched to 5 wt.\% in ${ }^{235} \mathrm{U}$. The effect of high Er-doping on the worth of control rods remains to be evaluated in a future study.

\section{Conclusions}

The results of the comparison between a $17 \times 17$ PWR assembly enriched to $10.27 \mathrm{wt} . \%$ in ${ }^{235} \mathrm{U}$ with an erbia content of 1 at.\% (i.e. $0.7 \mathrm{wt} . \%$ ) and a conventional $\mathrm{UO}_{2}$ fuel assembly (enriched to $5 \mathrm{wt} . \%$ in ${ }^{235} \mathrm{U}$ ) in terms of neutronics parameters such as multiplication factor, ${ }^{239} \mathrm{Pu}$ concentration, neutron spectrum, spectral index, beta effective and temperature reactivity coefficients are summarized below:

- Er-doped assembly can reach a burnup of $76 \mathrm{GWd} / \mathrm{MTU}$, more than twice the $36 \mathrm{GWd} / \mathrm{MTU}$ burnup of conventional fuel assembly but without exceeding the limit represented by the maximum criticality value.

- EoL ${ }^{239} \mathrm{Pu}$ concentration in Er-doped assembly is twice less than that in the conventional fuel assembly.

- Effective beta, as a function of burnup, decreases more slowly in Er-doped assembly than in the conventional fuel assembly.

- Fuel and moderator temperature reactivity coefficients of Er-doped assembly are at least as good as the conventional ones.

These results allow us to infer that, from a neutronic point of view, the performance of the erbia poisoned fuel assembly is at least as good as that of a conventional fuel assembly. In addition, the numerical analysis performed to assess the effects of erbia in a PWR fuel pin showed that, from a thermal-hydraulic point of view, the addition of 1 at.\% erbia to uranium oxide produces a very limited increase in maximum centerline temperature.

It can therefore be concluded that this kind of fuel assembly may represent an advantageous solution to achieve very high burnups, provided that mechanical 
Table 11. Fuel temperature coefficient.

\begin{tabular}{|c|c|c|c|c|c|}
\hline Configuration & Phase & $T_{\text {fuel }}\left[{ }^{\circ} \mathrm{C}\right]$ & $\Delta T$ & $k_{\text {inf }}[\mathrm{pcm}]$ & $\alpha_{\text {Dop }}\left[\mathrm{pcm} /{ }^{\circ} \mathrm{C}\right] @ \mathrm{BU}=0$ \\
\hline \multirow{6}{*}{${ }^{235} \mathrm{U}=10.27$ wt. $\%$ and $\mathrm{Er}=1$ at. $\%$} & $\begin{array}{l}\text { Initial } \\
\text { Final }\end{array}$ & $\begin{array}{l}540 \\
550\end{array}$ & 10 & $\begin{array}{l}1.323998 \\
1.323681\end{array}$ & -1.809 \\
\hline & $\begin{array}{l}\text { Initial } \\
\text { Final }\end{array}$ & $\begin{array}{l}540 \\
560\end{array}$ & 20 & $\begin{array}{l}1.323998 \\
1.323363\end{array}$ & -1.812 \\
\hline & $\begin{array}{l}\text { Initial } \\
\text { Final }\end{array}$ & $\begin{array}{l}540 \\
590\end{array}$ & 50 & $\begin{array}{l}1.323998 \\
1.322364\end{array}$ & -1.867 \\
\hline & $\begin{array}{l}\text { Initial } \\
\text { Final }\end{array}$ & $\begin{array}{l}540 \\
530\end{array}$ & -10 & $\begin{array}{l}1.323998 \\
1.324395\end{array}$ & 2.264 \\
\hline & $\begin{array}{l}\text { Initial } \\
\text { Final }\end{array}$ & $\begin{array}{l}540 \\
520\end{array}$ & -20 & $\begin{array}{l}1.323998 \\
1.324721\end{array}$ & 2.061 \\
\hline & $\begin{array}{l}\text { Initial } \\
\text { Final }\end{array}$ & $\begin{array}{l}540 \\
490\end{array}$ & -50 & $\begin{array}{l}1.323998 \\
1.325687\end{array}$ & 1.925 \\
\hline \multirow{3}{*}{${ }^{235} \mathrm{U}=5 \mathrm{wt} . \%$ and $\mathrm{Er}=0$ at. $\%$} & $\begin{array}{l}\text { Initial } \\
\text { Final }\end{array}$ & $\begin{array}{l}540 \\
590\end{array}$ & 50 & $\begin{array}{l}1.324021 \\
1.322389\end{array}$ & -1.864 \\
\hline & $\begin{array}{l}\text { Initial } \\
\text { Final }\end{array}$ & $\begin{array}{l}540 \\
530\end{array}$ & -10 & $\begin{array}{l}1.324021 \\
1.324346\end{array}$ & 1.853 \\
\hline & $\begin{array}{l}\text { Initial } \\
\text { Final }\end{array}$ & $\begin{array}{l}540 \\
490\end{array}$ & -50 & $\begin{array}{l}1.324021 \\
1.325723\end{array}$ & 1.939 \\
\hline \multirow{2}{*}{${ }^{235} \mathrm{U}=10.27$ wt. $\%$ and $\mathrm{Er}=0$ at. $\%$} & $\begin{array}{l}\text { Initial } \\
\text { Final }\end{array}$ & $\begin{array}{l}540 \\
590\end{array}$ & 50 & $\begin{array}{l}1.451792 \\
1.450069\end{array}$ & -1.637 \\
\hline & $\begin{array}{l}\text { Initial } \\
\text { Final }\end{array}$ & $\begin{array}{l}540 \\
490\end{array}$ & -50 & $\begin{array}{l}1.451792 \\
1.453604\end{array}$ & 1.717 \\
\hline
\end{tabular}

Table 12. Moderator temperature coefficient.

\begin{tabular}{|c|c|c|c|c|c|}
\hline Configuration & Phase & $T_{\bmod }\left[{ }^{\circ} \mathrm{C}\right]$ & $\Delta T$ & $k_{\text {inf }}[\mathrm{pcm}]$ & $a_{\text {Mod }}\left[\mathrm{pcm} /{ }^{\circ} \mathrm{C}\right] @ \mathrm{BU}=0$ \\
\hline \multirow{6}{*}{${ }^{235} \mathrm{U}=10.27$ wt. $\%$ and $\mathrm{Er}=1$ at. $\%$} & $\begin{array}{l}\text { Initial } \\
\text { Final }\end{array}$ & $\begin{array}{l}314 \\
324\end{array}$ & 10 & $\begin{array}{l}1.323998 \\
1.320593\end{array}$ & -19.473 \\
\hline & $\begin{array}{l}\text { Initial } \\
\text { Final }\end{array}$ & $\begin{array}{l}314 \\
334\end{array}$ & 20 & $\begin{array}{l}1.323998 \\
1.316882\end{array}$ & -20.406 \\
\hline & $\begin{array}{l}\text { Initial } \\
\text { Final }\end{array}$ & $\begin{array}{l}314 \\
364\end{array}$ & 50 & $\begin{array}{l}1.323998 \\
1.304301\end{array}$ & -22.812 \\
\hline & $\begin{array}{l}\text { Initial } \\
\text { Final }\end{array}$ & $\begin{array}{l}314 \\
304\end{array}$ & -10 & $\begin{array}{l}1.323998 \\
1.327357\end{array}$ & 19.116 \\
\hline & $\begin{array}{l}\text { Initial } \\
\text { Final }\end{array}$ & $\begin{array}{l}314 \\
294\end{array}$ & -20 & $\begin{array}{l}1.323998 \\
1.330423\end{array}$ & 18.238 \\
\hline & $\begin{array}{l}\text { Initial } \\
\text { Final }\end{array}$ & $\begin{array}{l}314 \\
264\end{array}$ & -50 & $\begin{array}{l}1.323998 \\
1.338473\end{array}$ & 16.336 \\
\hline \multirow{3}{*}{$\begin{array}{l}{ }^{235} \mathrm{U}=5 \mathrm{wt} . \% \text { and } \\
\mathrm{Er}=0 \text { at. } \%\end{array}$} & $\begin{array}{l}\text { Initial } \\
\text { Final }\end{array}$ & $\begin{array}{l}314 \\
364\end{array}$ & 50 & $\begin{array}{l}1.324021 \\
1.313438\end{array}$ & -12.172 \\
\hline & $\begin{array}{l}\text { Initial } \\
\text { Final }\end{array}$ & $\begin{array}{l}314 \\
304\end{array}$ & -10 & $\begin{array}{l}1.324021 \\
1.325459\end{array}$ & 8.192 \\
\hline & $\begin{array}{l}\text { Initial } \\
\text { Final }\end{array}$ & $\begin{array}{l}314 \\
264\end{array}$ & -50 & $\begin{array}{l}1.324021 \\
1.329337\end{array}$ & 6.040 \\
\hline \multirow{2}{*}{$\begin{array}{l}{ }^{235} \mathrm{U}=10.27 \mathrm{wt} . \% \text { and } \\
\mathrm{Er}=0 \text { at. } \%\end{array}$} & $\begin{array}{l}\text { Initial } \\
\text { Final }\end{array}$ & $\begin{array}{l}314 \\
364\end{array}$ & 50 & $\begin{array}{l}1.451792 \\
1.435615\end{array}$ & -15.523 \\
\hline & $\begin{array}{l}\text { Initial } \\
\text { Final }\end{array}$ & $\begin{array}{l}314 \\
264\end{array}$ & -50 & $\begin{array}{l}1.451792 \\
1.462448\end{array}$ & 10.038 \\
\hline
\end{tabular}


Table 13. Water density.

\begin{tabular}{llrl}
\hline$T_{\text {initial }}\left[{ }^{\circ} \mathrm{C}\right]$ & $T_{\text {final }}\left[{ }^{\circ} \mathrm{C}\right]$ & $\Delta T$ & $\begin{array}{l}\rho\left[\mathrm{kg} / \mathrm{m}^{3}\right] \\
\text { only water }\end{array}$ \\
\hline 314 & 314 & 0 & 702 \\
314 & 324 & 10 & 686 \\
314 & 334 & 20 & 669 \\
314 & 364 & 50 & 615 \\
314 & 304 & -10 & 718 \\
314 & 294 & -20 & 734 \\
314 & 264 & -50 & 779 \\
\hline
\end{tabular}

interaction between fuel and cladding does not constitute a strong limiting constraint. However, this aspect is out of the scope of this study.

\section{Nomenclature}

\begin{tabular}{|c|c|}
\hline at. $\%$ & percentage of number of atoms \\
\hline$\beta_{\text {eff }}$ & effective delayed neutron fraction \\
\hline BoL & beginning of life \\
\hline BWR & boiling water reactor \\
\hline$c_{p}$ & specific heat \\
\hline$D$ & subchannel hydraulic diameter \\
\hline EoL & end of life \\
\hline FTC & fuel temperature coefficient \\
\hline$G$ & gap thickness \\
\hline GWd & giga-watt day \\
\hline $\mathrm{GWd} / \mathrm{MTU}$ & giga-watt days per metric ton of uranium \\
\hline & $\begin{array}{l}\text { convective heat transfer coefficient } \\
\text { of the flow }\end{array}$ \\
\hline$n_{w}$ & convection coefficient \\
\hline$h_{G}$ & gap conductance \\
\hline$k$ & thermal conductivity \\
\hline$k_{c}$ & $\begin{array}{l}\text { thermal conductivity of the cladding } \\
\text { material }\end{array}$ \\
\hline$k_{f}$ & thermal conductivity of the fuel \\
\hline$k_{G}$ & thermal conductivity of the gap gas \\
\hline$L$ & characteristic length \\
\hline LWR & light water reactor \\
\hline $\mathrm{M} 5^{\circledR}$ & low-corrosion zirconium alloy \\
\hline MTC & moderator temperature coefficient \\
\hline $\mathrm{Nu}$ & Nusselt number \\
\hline $\mathrm{cm}$ & $\begin{array}{l}\text { per cent mille }- \text { unit of reactivity } \\
\text { corresponding to } 10^{-5} \Delta k / k\end{array}$ \\
\hline ppm & parts-per-million, $10^{-6}$ \\
\hline $\mathrm{Pr}$ & Prandtl number \\
\hline PWR & Pressurized water reactor \\
\hline & average linear power density \\
\hline$q^{\prime \prime \prime}$ & power density \\
\hline Re & Reynolds number \\
\hline$T_{B}$ & average bulk temperature \\
\hline$t_{c}$ & cladding material thickness \\
\hline$T_{\text {eff }}$ & effective fuel temperature \\
\hline$T_{\mathrm{pc}}$ & pellet centerline temperature \\
\hline$T_{\mathrm{ps}}$ & pellet surface temperature \\
\hline$T_{\text {we }}$ & external clad temperature \\
\hline
\end{tabular}

$\begin{array}{ll}T_{\mathrm{wi}} & \text { internal clad temperature } \\ v & \text { mean velocity of the fluid } \\ \text { wt.\% } & \text { percentage of weight } \\ Y & \text { young modulus } \\ \rho & \text { density of the fluid } \\ \mu & \text { dynamic viscosity of the fluid }\end{array}$

The APOLLO2 code is developed by CEA and co-owned by CEA, EDF and AREVA NP.

\section{References}

1. J. Duderstadt, L. Hamilton, Nuclear reactor analysis (John Wiley \& Sons, New York, 1976)

2. J. Porta, M. Asou, Erbium: alternative poison? Stabilisation additive? What future? Prog. Nucl. Energy 38, 347 (2001)

3. M. Asou, J. Porta, Prospects for poisoning reactor cores of the future, Nucl. Eng. Des. 168, 261 (1997)

4. J. Porta et al., Qualification of the neutronic efficiency of erbium at zero burnup, Prog. Nucl. Energy 38, 355 (2001)

5. OECD, Nuclear energy agency report no. 6224, very high burn-ups in light water reactors (OECD, Paris, 2006)

6. M. Yamasaki, The study on erbia credit super-high-burnup fuel with isotopically modified erbia, in ANS 2010 Winter Meeting, Las Vegas, November 7-11, 2010 (2010)

7. M. Yamasaki et al., Development of erbia-credit super high burnup fuel: experiments and numerical analyses, Nucl. Technol. 177, 63 (2012)

8. S. Yamanaka et al., Thermal and mechanical properties of (U, Er) $\mathrm{O}_{2}$, J. Nucl. Mater. 389, 115 (2009)

9. IAEA-THPH, Thermophysical properties of materials for nuclear engineering: a tutorial and collection data (IAEATHPH, Vienna, 2008)

10. R. Sanchez et al., APOLLO2 Year 2010, Nucl. Eng. Technol. 42, 474 (2010)

11. UK EPR, The pre-construction safety report, sub-chapters 4.2 (fuel system design) and 4.4 (thermal and hydraulic design) (UK EPR, 2012), available at: http://www.eprreactor.co.uk/scripts/ssmod/publigen/content/templates/ show.asp? $\mathrm{P}=290 \& \mathrm{~L}=\mathrm{EN}$

12. W.G. Luscher, K.J. Geelhood, Material Property Correlations: Comparisons between FRAPCON-3.4, FRAPTRAN 1.4 and MATPRO, US-NRC NUREG/CR-7024, August $2010(2010)$

13. M. Oguma, Cracking and relocation behaviour of nuclear fuel pellets during rise to power, Nucl. Eng. Des. 76, 35 (1983)

14. K.J. Geelhood, W.G. Luscher, C.E. Beyer, FRAPCON-3.4: A Computer Code for the Calculation of Steady-State Thermal-Mechanical Behavior of Oxide Fuel Rods for High Burnup, NUREG/CR-7022, PNNL-19418, Washington D.C. (2011), Vol. 1

15. T. Kozlowski, T. Downar, Pressurized water reactor MPX/ $\mathrm{UO}_{2}$ core transient benchmark final report, $\mathrm{NEA} / \mathrm{NSC} / \mathrm{DOC}$ (2006)20, Technical Report (OECD/NEA and US NRC, Paris, 2006)

16. U.S.NRC, Material Property Correlations: Comparisons between FRAPCON-3.4, FRAPTRAN 1.4, and MATPRO, March 2011 (2011) 
17. R. Gregg, A. Worrall, Effect of highly enriched/highly burnt $\mathrm{UO}_{2}$ fuels on nuclear design parameters and economics, in Advances in Nuclear Fuel Management III (ANFM 2003), Hilton Head Island, South Carolina, October 5-8, 2003 (2003)

18. J.R. Secker et al., Optimum Discharge Burnup and Cycle Lenght for PWRs, in Advances in Nuclear Fuel Management III (ANFM 2003), Hilton Head Island, South Carolina, October 5-8, 2003 (2003)
19. J.R. Lamarsh, A.J. Baratta, Introduction to nuclear engineering (Prentice Hall, Upper Saddle River, New Jersey, 2001)

20. R.D. Mosteller, The Doppler-defect benchmark: overview and summary of results, in Joint International Topical Meeting on Mathematics $\&$ Computation and Supercomputing in Nuclear Applications, Monterey, April 15-19, 2007 (2007)

21. S.C. McCutcheon, J.L. Martin, T.O. Barnwell Jr., Water quality, in Handbook of hydrology, edited by D.R. Maidment (McGraw-Hill, New York, 1993)

Cite this article as: Roberto Pergreffi, Davide Mattioli, Federico Rocchi, Neutronics characterization of an erbia fully poisoned PWR assembly by means of the APOLLO2 code, EPJ Nuclear Sci. Technol. 3, 8 (2017) 